\title{
Estructura de Personalidad en Pacientes con Depresión: Adaptación de un Instrumento y Resultados Preliminares
}

\author{
Personality Structure in Patients with Depression: \\ Adaptation of an Instrument and Preliminary Results
}

\author{
Guillermo de la Parra, Catalina Undurraga, Carla Crempien, \\ Camila Valdés, Paula Dagnino y Elyna Gómez-Barris \\ Pontificia Universidad Católica de Chile
}

\begin{abstract}
El funcionamiento de la personalidad puede ser un factor de vulnerabilidad en el desarrollo de trastornos depresivos e influirá en como se expresan en cada paciente. El diagnóstico de capacidades y vulnerabilidades estructurales de la personalidad favorecerá la planificación de la terapia. Se presenta el Cuestionario de Estructura del Diagnóstico Psicodinámico Operacionalizado (OPD-SQ), instrumento que evalúa la estructura de personalidad, sus fundamentos teóricos, proceso de traducción al español y adaptación. Se presentan resultados preliminares de su aplicación en muestras de conveniencia (muestra clínica: 192 pacientes con diagnóstico de depresión; muestra no clínica: 112 estudiantes y funcionarios de una universidad de Santiago, Chile). Se encontró una alta consistencia interna (alfa de Cronbach) del OPD-SQ y de las subescalas que lo componen, excepto para la escala Vínculos Externos. Se encontraron diferencias de los puntajes ( $t$ de Welch) entre muestra clínica y no clínica y correlaciones de Pearson directas y altas entre el OPD-SQ y nivel de sintomatología depresiva y distrés psicológico. Los resultados presentados sirven de base para futuros estudios que puedan aportar a su validación para su uso clínico y en investigación.
\end{abstract}

Palabras clave: estructura de personalidad, depresión, autorreporte, adaptación de instrumento

\begin{abstract}
Personality functioning may be a vulnerability factor for the development of depressive disorders and will influence how these are expressed in each patient. Diagnosing the structural capacities and vulnerabilities of a patient's personality will facilitate the planning of therapy. This article introduces the Operationalized Psychodynamic Diagnosis Structure Questionnaire (OPD-SQ), a personality structure assessment instrument, covering its theoretical background, its translation into Spanish, and its adaptation process. Preliminary results of its administration to convenience samples are presented (clinical sample: 192 patients diagnosed with depression; nonclinical sample: 112 students and administrative staff from a university in Santiago, Chile). High internal consistency (Cronbach's alpha) was found for the OPD-SQ and its subscales, except for the Attachment to External Objects scale. Differences were observed between the scores of the clinical and nonclinical samples (Welch's $t$-test), as well as direct and high Pearson's correlations coefficients between OPD-SQ and depressive symptomatology and psychological distress levels. The results presented lay the groundwork for future studies aimed at contributing to the validation of the OPD-SQ for use in clinical and research settings.
\end{abstract}

Keywords: personality structure, depression, self-report, instrument adaptation

Así como se ha cuestionado la unidimensionalidad de la depresión desde un punto de vista biológico, llegándose a plantear la necesidad de una "medicina personalizada" (Hasler, 2010), se han cuestionado también los diagnósticos descriptivos basados en síntomas o trastornos mentales, proponiéndose enfoques diagnósticos más comprensivos centrados en la persona, que van más allá de los síntomas, considerando los recursos y experiencia de enfermedad del paciente, entre otros aspectos (Salloum \& Mezzich, 2011). En este contexto, el tratamiento de la depresión debe orientarse a la persona del paciente, considerando la personalidad, que "tiñe" el cuadro depresivo. Para aproximarse a la relación entre depresión y personalidad,

Guillermo de la Parra, Departamento de Psiquiatría, Facultad de Medicina, Pontificia Universidad Católica de Chile, Santiago, Chile; Catalina Undurraga, Carla Crempien, Camila Valdés y Elyna Gómez-Barris, Escuela de Psicología, Pontificia Universidad Católica de Chile, Santiago, Chile; Paula Dagnino, Escuela de Psicología, Pontificia Universidad Católica de Chile y Facultad de Psicología, Universidad Alberto Hurtado, Santiago, Chile.

Este estudio contó con el apoyo del Fondo de Innovación para la Competitividad (FIC) del Ministerio de Economía, Fomento y Turismo de Chile, a través de la Iniciativa Científica Milenio, Fondo $N^{\circ}$ IS130005. También recibió apoyo de la Comisión Nacional de Ciencia y Tecnología, a través de los Proyectos FONDECYT de Postdoctorado No 3140402 y No 3140317 y del Proyecto FONDECYT $\mathrm{N}^{\mathrm{o}} 1130810$.

La correspondencia relativa a este artículo debe ser dirigida a Guillermo de la Parra, Centro de Salud Mental, Avda. Vicuña Mackenna 4860, Macul, Santiago, Chile. E-mail: gdelaparra@uc.cl 
de una manera clínicamente relevante, se hace necesario poder evaluar el funcionamiento de esta, especialmente respecto a capacidades y vulnerabilidades o déficits de la estructura de personalidad. De esta manera, se podrá focalizar el tratamiento en aquellos aspectos vulnerables de la estructura que subyacen a los síntomas.

En este trabajo se presenta la versión en español del Cuestionario de Funcionamiento Estructural OPDSQ (por la sigla en inglés Operationalized Psychodynamic Diagnostics Structure Questionnaire; Ehrenthal et al., 2012), que es producto del trabajo colaborativo entre investigadores chilenos y alemanes; estos últimos autores del instrumento original. Se trata de un cuestionario de autorreporte que evalúa dimensionalmente y de manera diferenciada capacidades y vulnerabilidades estructurales de la personalidad, basado en el Eje IV (Estructura) del Sistema de Diagnóstico Psicodinámico Operacionalizado (OPD-2; Grupo de Trabajo OPD, 2008). El instrumento OPD-SQ se desarrolla a partir de una concepción dinámica y evolutiva de la estructura de la personalidad, entendida como una organización de funciones psíquicas que permiten regular y responder a las demandas del mundo interno y externo. A través de 95 ítems en que las personas indican el grado en que estos las describen, el cuestionario mide el nivel de integración estructural de la personalidad, mediante la evaluación de cuatro dominios, los que, a su vez, presentan dos orientaciones: hacia el sí mismo y hacia los otros. Los dominios son: (a) capacidades cognitivas, (b) capacidades de manejo y/o regulación), (c) capacidades emocionales y (d) capacidades de vínculo. Estudios realizados en Alemania con muestras clínicas y no clínicas entregan evidencia a favor de la confiabilidad de la prueba, reportando una consistencia interna entre 0,71 y 0,78 para las diferentes escalas. En el presente artículo se desarrollan los fundamentos teóricos que están a la base del instrumento, se describe el proceso de traducción y traducción inversa y se presentan resultados preliminares de su comportamiento en pacientes con trastornos depresivos y población general.

\section{Personalidad y Depresión}

La relación entre personalidad y depresión es compleja y ha sido ampliamente discutida, dando lugar a diversos modelos teóricos que aportan a la comprensión de los mecanismos etiológicos y de comorbilidad, a la identificación de individuos con mayores riesgos y al abordaje terapéutico (Klein, Kotov \& Bufferd, 2011).

De acuerdo con Klein et al. (2011), es posible distinguir tres tipos de modelos de relación entre personalidad y depresión. Un primer grupo de modelos plantea que la depresión y la personalidad tendrían influencias causales compartidas, pero que no tendrían una relación causal entre ellas. Desde esta perspectiva, depresión y personalidad serían fenomenológicamente similares. Se podría entender la relación entre personalidad y depresión como un continuo donde los trastornos depresivos estarían en el polo extremo de ciertos rasgos de personalidad, o bien, se podría considerar que la personalidad es un precursor de la depresión, en el sentido de que individuos con un alto nivel de ciertos rasgos tendrían mayor riesgo de desarrollar un trastorno depresivo. Un segundo grupo de modelos propone que la personalidad tendría un efecto causal en el desarrollo y/o la mantención de la depresión. Es el caso del modelo predisposicional, en el que la vulnerabilidad de la personalidad, en interacción con otros factores moderadores o mediadores, tendría un rol en la génesis de la depresión. O bien, el modelo patoplástico, que propone que la personalidad tendría una influencia en la forma en que se expresa el trastorno depresivo, en cuanto a severidad, patrón de síntomas, respuesta al tratamiento, entre otros aspectos. Por último, están aquellos modelos que también atribuyen una relación causal entre personalidad y depresión, pero en el sentido inverso, es decir, la depresión ejercería una influencia en la personalidad, ya sea de manera concomitante, en que los rasgos de personalidad se verán distorsionados o afectados mientras dura el episodio depresivo, o bien, teniendo un efecto perdurable en el tiempo, como propone el modelo de consecuencias o "cicatrices".

El presente trabajo se enmarca en el segundo grupo de modelos. Se entiende el concepto de personalidad como un factor que puede ser un predisponente para el desarrollo de trastornos depresivos (vulnerabilidad) y también una influencia en cómo se expresan dichos trastornos, influencia que determinará la severidad de los síntomas, la experiencia de la depresión, la respuesta al tratamiento, entre otras. La mirada que se propone, a partir del OPD-2; Grupo de Trabajo OPD, 2008), es una mirada dimensional en oposición a una mirada categorial, en la que las diferentes funciones de la estructura de personalidad pueden ser evaluadas de manera independiente, de tal manera que en terapia se puede trabajar una vulnerabilidad funcional, por ejemplo, descontrol de impulsos, apoyado en una buena capacidad funcional en el aspecto de la autopercepción. La perspectiva dimensional es compartida por otros instrumentos de la literatura psicodinámica, como el Shedler-Westen Assessment Procedure (SWAP; Shedler \& Westen, 2007), el Structured Interview of Personality Organization (STIPO; Clarkin, Caligor, Stern \& Kernberg, 2004), que 
sigue el modelo de Otto Kernberg, o el Mental Functioning Dimension del Psychodynamic Diagnostic Manual (PDM Task Force, 2006). El sistema DSM-5 como tal no logró evolucionar hacia una mirada dimensional de los trastornos de personalidad (Florenzano \& Guerrero, 2014), quedando relegada esta perspectiva a la sección III, "Modelos y Medidas Emergentes", para la cual el Level of Personality Functioning Scale (LPFS; Bender, Morey \& Skodol, 2011; Morey et al., 2011) está siendo aplicado para el estudio de diversas cohortes clínicas. Para una comparación entre los sistemas LPFS del DSM-5 y OPD-2 véase Zimmermann et al. (2012).

La mayoría de estas aproximaciones, incluyendo el OPD-2 en su versión original, evalúan mediante jueces con el uso de manuales. Si bien tienen una alta confiabilidad, resultan onerosos en cuanto al tiempo requerido tanto para entrenar a los jueces-terapeutas como en la aplicación misma de los instrumentos a través de entrevistas de una a dos horas de duración (Grupo de Trabajo OPD, 2008). Es en ese sentido que un instrumento de autorreporte como el que se presenta a continuación puede representar un aporte a la clínica y la investigación de la estructura de personalidad y su relación con la depresión.

\section{El Diagnóstico Psicodinámico Operacionalizado: Fundamentos}

El OPD-2, el cual da origen al cuestionario de autorreporte, integra criterios descriptivos y sintomatológicos con dimensiones psicodinámicas de relevancia clínica, que orientan al clínico en la indicación y planificación de la psicoterapia y permiten la evaluación de los cambios obtenidos por medio de ella. El OPD-2 organiza la información diagnóstica en cinco ejes: Eje I Vivencia de enfermedad y prerrequisitos para el tratamiento, Eje II Relación (patrones relacionales disfuncionales), Eje III Conflicto, Eje IV Estructura y Eje V Trastornos psíquicos y psicosomáticos (Grupo de Trabajo OPD, 2008).

Para el OPD-2, la estructura corresponde:

al tejido de disposiciones psíquicas, que abarca todo lo que en la vivencia y conducta del individuo se desarrolla de manera regular y repetitiva (consciente o alejado de la consciencia). La estructura determina el estilo personal y permanente a través del cual el individuo puede recuperar su equilibrio intrapsíquico e interpersonal. La estructura no dañada posee la disposición flexible y creativa de funciones que tienen un efecto regulador y adaptativo, intrapsíquico e interpersonal. (Grupo de Trabajo OPD, 2008, p. 135)

La estructura sería dinámica, permitiendo la regulación y, al mismo tiempo, manteniendo un equilibrio homeostático que no es rígido ni inmutable. A pesar de que los cambios serían lentos, la estructura debería ir evolucionando a lo largo de la vida, por medio de la integración de nueva información que permite establecer nuevas reglas de regulación (Grupo de Trabajo OPD, 2008).

En la medida que la estructura psíquica se va consolidando en base a dos tareas vitales, estructurar autonomía e identidad y vincularse (Blatt \& Luyten, 2009), la consecuencia es que la estructura psíquica se encuentra constituida por funciones orientadas a la regulación del self y a su relación con los objetos internos y externos (Grupo de Trabajo OPD, 2008), y son justamente estas funciones las que son evaluadas a través del instrumento que se presenta en el presente artículo.

Es así que el eje IV Estructura del manual OPD-2 considera cuatro dominios funcionales, cada uno con funciones estructurales orientadas al self y a las relaciones objetales. Cada función, a su vez, se compone de tres subfunciones como se aprecia en la Tabla 1 (Grupo de Trabajo OPD, 2008). En las capacidades estructurales referidas al self del OPD-2, el self "se manifiesta a través de la función reflexiva, el yo se toma a sí mismo como objeto de la percepción" (Grupo de Trabajo OPD, 2008, p. 139). La autorreflexión permite desarrollar una imagen de sí mismo que, si es constante y coherente, se logra la vivencia de identidad. Al mismo tiempo, pudiera favorecer la percepción de valoración que otros tienen de sí mismo y con ello valorarse (autoestima). El self integra todo lo expuesto en funciones psíquicas y disposiciones capaces de regular procesos internos (afectos, impulsos, autoestima). A su vez, el uso y la disponibilidad de defensas flexibles que resultan de la internalización de un sistema normativo adecuado pueden también considerarse como funciones reguladoras (Grupo de Trabajo OPD, 2008). Todos los aspectos del self encuentran su correspondencia con los objetos externos. Estas vivencias relacionales constituyen el fundamento para el desarrollo y regulación del self. Al mismo tiempo que se desarrolla una percepción reflexiva del self, se pueden describir las percepciones realistas del objeto. Las percepciones realistas son posibles en la medida de que el self pueda diferenciarse del objeto a través del establecimiento de límites entre ambos y la aceptación de que el objeto posee una realidad propia e independiente de él (Grupo de Trabajo OPD, 2008). 
El self logra manejarse en las relaciones objetales en la medida que se encuentren disponibles las funciones de establecimiento de vínculos y la protección de ellos, frente a los propios afectos e impulsos. Esto implica que el self es capaz de definir y diferenciar sus propios intereses del de los demás. A su vez, es necesaria también la capacidad de anticipación de la reacción de los otros para lograr una regulación self y objeto. Por otra parte, para poder experimentar a los demás como objetos separados del sí mismo, es necesario poder darse a entender frente al otro. Esto último se logra a través de una adecuada expresión emocional, lo que permite llegar emocionalmente al objeto y/o ser afectado de igual forma por los demás. El poder experimentarse como objetos separados (el self y los otros) depende, al mismo tiempo, de que el sujeto logre darse a entender comunicativamente. Por último, es de gran relevancia contar con la capacidad para situarse transitoriamente en el mundo interno del otro para obtener todo lo descrito anteriormente (Grupo de Trabajo OPD, 2008). Las funciones del self y de la relación con los otros (objetos) que se acaban de describir se encuentran operacionalizadas en las dimensiones del Eje IV OPD-2, tal como se ilustra en la Tabla 1 y vertidas en el instrumento OPD-SQ que se presenta más adelante.

Tabla 1

Funciones Estructurales de la Personalidad Según el Eje IV (Estructura) del OPD-2

\begin{tabular}{|c|c|c|}
\hline Dominio & Función & Subfunción \\
\hline \multirow[t]{2}{*}{ Capacidades cognitivas } & Percepción de sí mismo & $\begin{array}{l}\text { Autorreflexión } \\
\text { Diferenciación afectiva } \\
\text { Identidad }\end{array}$ \\
\hline & Percepción del objeto & $\begin{array}{l}\text { Diferenciación self-objeto } \\
\text { Percepción de objeto total } \\
\text { Percepción realista del objeto }\end{array}$ \\
\hline \multirow[t]{2}{*}{ Capacidad de manejo } & Autorregulación & $\begin{array}{l}\text { Manejo de impulsos } \\
\text { Tolerancia afectiva } \\
\text { Regulación de la autoestima }\end{array}$ \\
\hline & Regulación de la relación con el objeto & $\begin{array}{l}\text { Protección de las relaciones } \\
\text { Regulación de los intereses } \\
\text { Anticipación }\end{array}$ \\
\hline \multirow[t]{2}{*}{ Capacidad emocional } & Comunicación emocional interna & $\begin{array}{l}\text { Vivencia de los afectos } \\
\text { Uso de fantasías } \\
\text { Self corporal }\end{array}$ \\
\hline & Comunicación emocional externa & $\begin{array}{l}\text { Establecer contacto } \\
\text { Comunicación de los afectos } \\
\text { Empatía }\end{array}$ \\
\hline \multirow[t]{3}{*}{ Capacidad de vínculo } & Vínculo con objetos internos & $\begin{array}{l}\text { Internalización } \\
\text { Uso de introyectos } \\
\text { Variedad de vínculos }\end{array}$ \\
\hline & Vínculo con objetos externos & $\begin{array}{l}\text { Capacidad de vincularse } \\
\text { Aceptar ayuda }\end{array}$ \\
\hline & & Desprenderse de vínculos, s \\
\hline
\end{tabular}

En resumen, la evaluación de este eje permite no solo tener una apreciación del nivel de integración estructural de la personalidad, en un continuo de mejor a peor funcionamiento, sino evaluar específicamente las vulnerabilidades (que eventualmente subyacen a la depresión) y fortalezas estructurales del sujeto, lo que facilitaría, a nivel clínico, el establecimiento de focos psicoterapéuticos a trabajar (Grupo de Trabajo OPD, 2008) y, a nivel científico, conocer el tipo de déficit de los diferentes cuadros psicopatológicos.

Similar a como lo hacen otros instrumentos que miden funciones de la estructura de personalidad como los mencionados al principio, la evaluación del OPD-2 requiere realizar una entrevista psicodinámica específica, de una duración de una a dos horas, en la que se exploran los patrones de relación maladaptativos, los conflictos y el funcionamiento estructural, explorando la capacidad de verse a sí mismo y a los objetos (Grupo de Trabajo OPD, 2008). Un instrumento de autorreporte, como el que se presenta aquí, que permita 
medir el nivel de funcionamiento estructural y, diferenciadamente, las distintas capacidades estructurales, puede significar un importante aporte para el trabajo clínico y de investigación.

\section{El Cuestionario de Evaluación de Funciones de la Personalidad OPD-SQ}

El OPS-SQ es un cuestionario auto-aplicado que mide el nivel de integración estructural, a través de las cuatro dimensiones o capacidades estructurales mencionadas. Como se señaló anteriormente, cada una de estas dimensiones tiene dos orientaciones, al sí mismo y a los otros (objetos), con lo que el instrumento se conforma de ocho subescalas, que se construyeron teóricamente en base al manual OPD-2 (2008) y que se describirán a continuación. Estas se despliegan en 95 afirmaciones que corresponden a aspectos de autodescripción a los que el sujeto debe responder en una escala Likert de cinco puntos (desde 1 totalmente en desacuerdo a 5 totalmente de acuerdo; véase el Anexo). Los 95 ítems pretenden cubrir las funciones psíquicas descritas en la Tabla 1:

1. Capacidades cognitivas: se evalúan a través de 29 afirmaciones y se divide en la subescala de Percepción de Sí Mismo (compuesta por 12 afirmaciones) y la subescala Percepción del Objeto (compuesta por 17 afirmaciones).

2. Capacidades de manejo y/o regulación: se evalúa mediante 25 afirmaciones y se divide en la subescala de Autorregulación (compuesta por 13 afirmaciones) y la subescala Regulación de la Relación con el Objeto (compuesta por 12 afirmaciones).

3. Capacidades emocionales: se evalúa a través de 25 afirmaciones y se divide en la subescala de Comunicación Emocional Interna (compuesta por 11 afirmaciones) y la subescala Comunicación Emocional Externa (compuesta por 14 afirmaciones).

4. Capacidad de vínculo: se evalúa mediante 16 afirmaciones y se divide en la subescala Vínculos Internos (compuesta por 8 afirmaciones) y la subescala Vínculos Externos (compuesta por 8 afirmaciones).

Los autores del instrumento permiten no más de un valor perdido —un ítem sin contestar- por subescala para considerar el instrumento para su evaluación.

En la Tabla 2 se describen las subescalas del instrumento, indicando las subfunciones que estas incluyen, ítems de ejemplo de cada subescala y los alfa de Cronbach.

El instrumento entrega puntajes parciales para cada una de las subescalas y un puntaje total del funcionamiento estructural del sujeto. Un peor funcionamiento estructural queda expresado en puntajes más altos en las subescalas y la escala total.

Los creadores del instrumento original aportan evidencia a favor de la validez del instrumento para su uso en investigación en un estudio realizado en Alemania (Ehrenthal et al., 2012). Dicho estudio se realizó en una muestra de 1112 individuos, constituida por tres submuestras: (a) muestra no clínica, (b) pacientes en psicoterapia ambulatoria y (c) pacientes hospitalizados. Principalmente, se entregó evidencia de la relación con otras variables, encontrándose una correlación directa y alta con el Inventario de Síntomas SCL-27 (Hardt, Egle, Kappis, Hessel \& Brähler, 2004) y una correlación inversa con la subescala Apego Seguro y directa con las subescalas de Apego Ansioso, Evitativo y de Apego Preocupado del Inventario Relationship Styles Questionnaire (RSQ; Bartholomew \& Horowitz, 1991). En la misma línea, se observó una correlación directa con la dimensión Neuroticismo e inversa con las dimensiones Apertura, Amabilidad y Consciencia del modelo de personalidad Big Five, medidas mediante el Big Five Short Form (BF-24-AM; Herzberg \& Brähler, 2006). También se encontró que el OPD-SQ presentaba diferencias entre la muestra clínica y la muestra no clínica, encontrando un tamaño grande del efecto, según los criterios de Cohen $(d=1,50)$. Finalmente, también se encontró evidencia a favor de la confiabilidad del instrumento, presentando una alta consistencia interna en cada una de las escalas (entre 0,71 y 0,78 ). 
Tabla 2

Resumen de las Subescalas del OPD-SQ, Subfunciones Incluidas, Ítems de Ejemplo y Alfa de Cronbach

\begin{tabular}{|c|c|c|c|c|c|c|}
\hline \multirow[b]{2}{*}{ Subescala } & \multirow[b]{2}{*}{ Subfunción incluida } & \multirow[b]{2}{*}{$\begin{array}{l}\mathrm{N}^{\circ} \text { de } \\
\text { ítems }\end{array}$} & \multirow[b]{2}{*}{ Ítem de ejemplo } & \multicolumn{3}{|c|}{ Alfa de Cronbach } \\
\hline & & & & $\begin{array}{l}\text { Muestra } \\
\text { no clínica }\end{array}$ & $\begin{array}{l}\text { Muestra } \\
\text { clínica }\end{array}$ & $\begin{array}{l}\text { Muestra } \\
\text { total }\end{array}$ \\
\hline \multirow{3}{*}{$\begin{array}{l}\text { Percepción de Sí } \\
\text { Mismo }\end{array}$} & Autorreflexión & 4 & Me resulta muy difícil describirme a mí mismo/a. & 0,91 & 0,92 & 0,93 \\
\hline & Diferenciación afectiva & 4 & A menudo no tengo claro qué es exactamente lo que estoy sintiendo. & & & \\
\hline & Identidad & 4 & A veces afloran cosas en mí que no calzan conmigo. & & & \\
\hline \multirow[t]{3}{*}{ Percepción del Objeto } & Diferenciación self-objeto & 7 & $\begin{array}{l}\text { A veces dudo si alguien está pensando algo de mí o si solo es mi } \\
\text { imaginación. }\end{array}$ & 0,83 & 0,86 & 0,88 \\
\hline & Percepción de objeto total & 4 & O la otra persona está en mi misma onda o no vamos a funcionar. & & & \\
\hline & Percepción realista del objeto & 6 & Los demás me dicen que siempre vuelvo a elegir a los amigos equivocados. & & & \\
\hline \multirow[t]{3}{*}{ Autorregulación } & Manejo de impulsos & 4 & A veces estoy tan furioso que no puedo responder por lo que hago. & 0,86 & 0,87 & 0,89 \\
\hline & Tolerancia afectiva & 5 & Mis emociones son a veces tan intensas que me asustan. & & & \\
\hline & Regulación de la autoestima & 4 & Cuando alguien me critica, me resulta difícil superarlo. & & & \\
\hline \multirow[t]{2}{*}{$\begin{array}{l}\text { Regulación de la } \\
\text { Relación con el Objeto }\end{array}$} & $\begin{array}{l}\text { Regulación de la relación con el } \\
\text { objeto }\end{array}$ & 6 & Cuando me enojo, tiendo hacer daño en mis relaciones. & 0,83 & 0,83 & 0,85 \\
\hline & Anticipación & 6 & A veces juzgo mal cómo mi conducta afecta a los demás. & & & \\
\hline \multirow{3}{*}{$\begin{array}{l}\text { Comunicación } \\
\text { Emocional Interna }\end{array}$} & Vivencia de los afectos & 4 & Me cuesta percibir mis emociones. & 0,73 & 0,77 & 0,80 \\
\hline & Uso de las fantasías & 3 & Mis fantasías e ideas me vitalizan y enriquecen. & & & \\
\hline & Self corporal & 4 & A menudo soy incapaz de percibir bien mi cuerpo. & & & \\
\hline \multirow{3}{*}{$\begin{array}{l}\text { Comunicación } \\
\text { Emocional Externa }\end{array}$} & Establecer contacto & 4 & Me resulta difícil establecer contacto con otras personas. & 0,78 & 0,84 & 0,84 \\
\hline & Comunicación de los afectos & 6 & Me han dicho que muestro muy poco mis sentimientos. & & & \\
\hline & Empatía & 4 & Cuando alguien lo está pasando mal, suelo preocuparme. & & & \\
\hline \multirow[t]{2}{*}{ Vínculos Internos } & Internalización & 4 & A menudo tiendo a pensar en ciertas personas que podrían dañarme. & 0,86 & 0,84 & 0,87 \\
\hline & Uso de introyectos & 4 & Me resulta difícil hacer algo bueno para mí. & & & \\
\hline \multirow[t]{2}{*}{ Vínculos Externos } & Aceptar ayuda & 4 & Me resulta difícil pedir ayuda a los demás. & 0,70 & 0,65 & 0,71 \\
\hline & $\begin{array}{l}\text { Desprenderse de vínculos, } \\
\text { separarse }\end{array}$ & 4 & Las separaciones y despedidas son muy difíciles para mí. & & & \\
\hline
\end{tabular}




\section{Método}

\section{Proceso de Adaptación en Chile}

Traducción. La traducción y traducción inversa del OPD-SQ fue un trabajo en conjunto con los creadores del instrumento, investigadores y un tesista, miembros del Instituto Milenio de Investigación en Depresión y Personalidad (MIDAP, por su sigla en inglés). En este procedimiento se tuvo especial cuidado de apegarse fielmente a la versión alemana original. Para ello fue necesario contar con personas cuyo primer idioma fuera el español o el alemán. Se realizó una primera traducción al español con la participación de uno de los autores de este artículo, quien estuvo a cargo de la traducción del Manual del OPD-2 (Grupo de Trabajo OPD, 2008), junto con una psicóloga bilingüe. Esta primera versión fue revisada por un no psicólogo con conocimientos de alemán, para una primera aproximación a la inteligibilidad del instrumento.

Después de una discusión técnica de cada ítem por parte de los autores del presente artículo, se seleccionaron cinco jueces chilenos, psicólogos o psiquiatras, que tuvieran nivel avanzado de alemán, para que revisaran en detalle la primera versión en español del instrumento y la compararan con la versión alemana original. A partir de ello, se obtuvieron cinco versiones. Tres expertos en OPD-2, co-autores de este artículo revisaron y seleccionaron las versiones, contrastándolas con el marco teórico del OPD-SQ y revisando si las traducciones correspondían a lo que decía medir cada uno de los ítems del instrumento. A partir de este análisis se construyó la segunda versión al español, la cual fue enviada al grupo de trabajo del OPD-2 en Alemania para su traducción inversa (Cardoso Ribeiro, Gómez-Conesa \& Hidalgo Montesinos, 2010).

Un grupo de estudiantes alemanes cuyo segundo idioma era el español retradujeron la versión hispana, creando una versión alemana que fue comparada con la original. En ese momento se entró a un proceso de discusión y análisis con los autores alemanes y el equipo chileno, que dio como resultado una tercera versión, la cual se entregó para su análisis de comprensibilidad a un grupo de psicólogos y psiquiatras (12) de la Unidad de Psicoterapia del Departamento de Psiquiatría de la Pontificia Universidad Católica de Chile, a profesionales del Instituto Chileno de Trastornos de la Personalidad y a personas que no tuvieran relación con psicología y/o psiquiatría. En cada etapa de este proceso, hubo distintas disparidades entre los evaluadores. En las primeras etapas hubo dificultades en la traducción de 57 ítems, es decir, 60\% de los ítems del instrumento. Por esta razón y con el fin, además, de poder captar finamente el nivel de intensidad de los adjetivos del enunciado, se hizo necesario utilizar un tercer idioma, el inglés. El nivel de intensidad de los adjetivos fue una de las mayores dificultades en la discusión entre el equipo alemán y chileno y entre las distintas traducciones al español, como se aprecia en la Tabla 3. Otro de los problemas fue que algunos de los adjetivos propuestos en español hacían referencias a experiencias afectivas, siendo que en el enunciado original hacían referencia a procesos cognitivos o viceversa, como se ejemplifica en la Tabla 3. Después de cada traducción y traducción inversa los desacuerdos fueron disminuyendo, hasta desaparecer.

Una vez que la tercera versión fue revisada por los distintos grupos clínicos mencionados anteriormente, se realizó la primera aplicación piloto del instrumento en pacientes de estrato socioeconómico medio-bajo de una institución privada. A partir de esas experiencias, se construyó una cuarta versión en español y fue enviada nuevamente al grupo de trabajo alemán. Esta versión fue discutida por ambos grupos, dando como resultado la versión final. Los equipos de evaluadores tenían dudas sobre la comprensión de ciertos enunciados, específicamente, en enunciados que comenzaban con palabras como Frecuentemente y A menudo, dado a que estos ítems debían ser respondidos en una escala Likert que también cuantificaba. Sin embargo, los pacientes que participaron, que demoraron en promedio entre 20 a 25 minutos en completarlo, no refirieron dificultades en la comprensión de los enunciados cuando se les preguntó directamente acerca de ello (un 1,3\% de la muestra no completó el instrumento; tampoco los evaluadores que aplicaron el instrumento reportaron dificultades al ser consultados. Si bien esta información fue recogida por algunos de los autores del presente trabajo, esta no se objetivó de acuerdo a alguna metodología específica (véanse más adelante las limitaciones del estudio). Pacientes con diagnóstico de trastornos graves de personalidad manifestaron en ocasiones sentirse inquietados por algunas de las afirmaciones, por lo que en estos casos es recomendable su uso en compañía de profesionales.

\section{Aplicación a una muestra chilena: resultados preliminares.}

Participantes. La muestra total consistió en 304 participantes mayores de 18 años de las regiones Metropolitana y de Aysén de Chile. Los datos de cuatro personas (1,3\%) fueron descartados, debido a que no completaron el número mínimo de ítems del OPD-SQ que permite el cálculo del puntaje total de la escala, es 
decir, omitieron más de un ítem por subescala, como se explica anteriormente. Del total de la muestra, 112 participantes, seleccionados por conveniencia, formaron parte de la muestra no clínica, la cual estuvo compuesta por estudiantes universitarios de dos instituciones universitarias y trabajadores de la misma universidad. Fueron excluidos de esta muestra aquellos participantes que reportaron encontrarse en tratamiento psicológico al momento del estudio.

En el caso de la muestra no clínica, el contacto de los participantes varió en función del centro de estudios (flyers o correo electrónico), pero no fueron ni sus profesores ni sus jefaturas quienes realizaron la invitación, sino miembros del equipo de investigación, en forma de una convocatoria abierta, para garantizar voluntariedad de su participación.

La muestra clínica, también recolectada por conveniencia, consistió en 192 participantes, quienes solicitaron atención en los siete centros de atención, tanto públicos como privados, donde se realizó este estudio. Se incluyeron en la muestra todos aquellos pacientes con diagnóstico de depresión realizado por los profesionales de los centros de atención (psicólogos y/o psiquiatras) y que respondieron favorablemente a la invitación a participar del estudio. Fueron excluidos todos los menores de 18 años, los consultantes por abuso de sustancia, con síntomas psicóticos o disfunción cognitiva.

El mecanismo de invitación de los participantes varió de acuerdo al centro donde fueron reclutados. En el caso de la muestra clínica, en el Centro de Atención Psicológica de la Universidad Gabriela Mistral fue la secretaria quien contactó a los pacientes y realizó la invitación a participar en la investigación; en la Unidad de Psicoterapia Adultos de la Unidad de Salud Mental fueron dos asistentes de investigación quienes concurrieron al Centro de Atención para invitar de forma presencial a los participantes; en los Centros Comunitarios de Salud Mental (COSAM) de las comunas de Macul, Nuñoa, Independencia, Conchalí y La Pintana los participantes fueron consultados por su disposición a recibir información sobre el estudio por profesionales de los mismos centros y, aquellos pacientes que estuvieron de acuerdo con ser contactados para recibir información, fueron contactados por una asistente de investigación, quien los invitaba a participar en el estudio.

No se cuenta con un registro preciso del porcentaje de invitados a participar que accedió a hacerlo.

Las características sociodemográficas de los participantes se encuentran resumidas en la Tabla 4 . Se encontró que las muestras clínica y no clínica presentan diferencias en edad, $t(260)=-12,22, p<0,001$, sexo, test exacto de Fisher $p<0,001$, escolaridad, test exacto de Fisher $p<0,001$, y ocupación, test exacto de Fisher $p<0,001$. La muestra clínica es de mayor edad que la no clínica. Respecto de la variable sexo, la muestra clínica está conformada por alrededor de un $81 \%$ de mujeres, en cambio, la muestra no clínica presenta un porcentaje menor de mujeres (30,36\%). En cuanto al nivel de escolaridad alcanzado, la muestra clínica presenta una mayor variabilidad, contando con sujetos distribuidos en las distintas categorías (desde analfabeto hasta educación universitaria o más). La muestra no clínica, por su parte, se concentra solo en dos categorías: educación media completa y universitaria o más. Por último, respecto de la ocupación, la muestra no clínica está conformada mayoritariamente por estudiantes $(83,64 \%)$, a diferencia de la muestra clínica, que presenta mayor variabilidad de ocupaciones y un menor porcentaje de estudiantes.

\section{Instrumentos.}

Inventario de Depresión de Beck (BDI-I; Beck, Ward, Mendelson, Mock \& Erbaugh, 1961). Es un cuestionario de autorreporte para la evaluación de sintomatología depresiva. Ha sido traducido a diversos idiomas y es ampliamente usado en investigación a nivel nacional e internacional (Alvarado, Vega, Sanhueza \& Muñoz, 2005). El instrumento consta de 21 ítems con cuatro afirmaciones, puntuadas en una escala de 0 a 3 puntos (e.g., " Me siento triste continuamente y no puedo dejar de estarlo", "Continuamente me culpo de todo lo que va mal"). Una mayor puntuación indica una mayor sintomatología depresiva. Presenta adecuada consistencia interna, con un coeficiente alfa de Cronbach de 0,86 para población clínica y 0,81 para la población no clínica (Beck, Steer \& Carbin, 1988). La versión chilena muestra que es un instrumento apropiado para evaluar sintomatología depresiva, con un grado de consistencia interna adecuado $(\alpha=0,92)$. Valdés et al. (2017) encontraron que el instrumento presentaba una estructura de un factor estable al ser probada en una muestra independiente, $\chi^{2}(189, N=569)=463,53, p<0,01$, RMSEA $=0,051$, CFI $=0,979$. No se encontraron diferencias en la estructura factorial del instrumento al evaluar la invarianza separadamente entre ambos sexos. También sugirieron considerar 14 puntos como el punto de corte para distinguir entre la población con (puntaje mayor que 14) y sin diagnóstico conocido. 
Tabla 3

Ejemplo de Desacuerdos Entre la Traducción Inversa al Alemán y la Versión Original, de Acuerdo a Comentarios de los Creadores del OPD-SQ

\begin{tabular}{lll}
\hline Ítem $\quad$ Primera traducción $\quad$ Comentarios del grupo alemán \\
\hline
\end{tabular}

Nivel de intensidad de los adjetivos

2 Muchas veces actúo sin pensar cuando estoy furioso.

$54 \quad$ Me han dicho repetidas veces que tengo poca consideración por las necesidades de los demás.
La palabra en alemán wütend (furioso) (retraducción al alemán) es una expresión mucho más fuerte que sehr aufgebracht (versión original). Se sugiere la palabra enojado, pues estaría más acorde con lo señalado.

En la versión original dice muy poca (zu wenig), lo cual es un poco más fuerte que poner solo poca.
Muchas veces actúo sin pensar cuando estoy enojado.

Me han dicho repetidas veces que tengo muy poca consideración por las necesidades de los demás.

Procesos cognitivos y experiencias afectivas

15 Siento a las demás personas o muy cercanas o muy ajenas.

$40 \quad$ No tengo una buena percepción de mí mismo/a.
Este ítem tiene que ver con la percepción del objeto y no sobre cuán bien uno se puede relacionar con otros.

Tenemos la impresión de que hubo un mal entendido que probablemente tiene que ver con la palabra específica en alemán Selbstbewusstsein, la cual significa no tener una buena autoestima, más que tener una mala percepción de sí mismo.
Percibo a los otros como muy familiares o muy extraños.

No tengo una buena autoestima. 
Tabla 4

Estadísticos Descriptivos de Variables Sociodemográficas para la Muestra Clínica, Muestra No Clínica y Muestra Total

\begin{tabular}{|c|c|c|c|}
\hline \multirow{2}{*}{ Variable } & Muestra no clínica & Muestra clínica & Muestra total \\
\hline & $n(\%)$ & $n(\%)$ & $N(\%)$ \\
\hline Edad: media (desviación estándar) & $22,20(7,34)$ & $37,71(14,35)$ & $31,89(14,34)$ \\
\hline Sexo: $n$ mujeres (\% de mujeres) & $34(30,36)$ & $151(80,75)$ & $185(61,9)$ \\
\hline \multicolumn{4}{|l|}{ Escolaridad } \\
\hline Analfabeto & - & $1(0,55)$ & $1(0,34)$ \\
\hline Básica incompleta & - & $4(2,19)$ & $4(1,36)$ \\
\hline Básica completa & - & $8(4,37)$ & $8(2,72)$ \\
\hline Media incompleta & - & $12(6,56)$ & $12(4,08)$ \\
\hline Media completa & $93(83,78)$ & $90(49,18)$ & $183(62,25)$ \\
\hline Técnico superior & - & $32(17,48)$ & $32(10,89)$ \\
\hline Universitaria o más & $18(16,22)$ & $36(19,67)$ & $54(18,36)$ \\
\hline \multicolumn{4}{|l|}{ Ocupación } \\
\hline Dueña de casa & $2(1,82)$ & $8(4,84)$ & $10(3,64)$ \\
\hline Estudiante & $92(83,64)$ & $46(27,88)$ & $138(50,18)$ \\
\hline Trabajador dependiente & $1(0,90)$ & $52(31,52)$ & $53(19,27)$ \\
\hline Trabajador independiente & & $15(9,09)$ & $15(5,45)$ \\
\hline Cesante & & $16(9,70)$ & $16(5,82)$ \\
\hline Con licencia & $15(13,64)$ & $11(6,67)$ & $26(9,46)$ \\
\hline Pensionado & & $8(4,85)$ & $8(2,91)$ \\
\hline Jubilado & & $9(5,45)$ & $9(3,27)$ \\
\hline
\end{tabular}

Cuestionario de Resultados (Outcome Questionnaire - OQ-45.2). Desarrollado por Lambert et al. (1996), es una escala de autorreporte de 45 ítems puntuados en escala de 0 a 4 , que permite medir el distrés psicológico en tres áreas del funcionamiento general e interpersonal del paciente en el momento actual: (a) sintomatología (25 ítems; e.g., "Me canso rápidamente"), (b) relaciones interpersonales (11 ítems; e.g., "Me siento contento con mi matrimonio/pareja") y (c) rol social (5 ítems; e.g., "Trabajo/estudio tan bien como lo hacía antes"). Estudios en Chile han mostrado que es un instrumento confiable y válido (consistencia interna $\alpha=0,93$; confiabilidad test-retest $r=0,84$; correlaciones que varían entre 0,53 y 0,88 con otros instrumentos similares; Lambert et al., 1996; Umphress, Lambert, Smart, Barlow \& Clouse, 1997) en su sensibilidad a la psicopatología y al cambio (Vermeersch, Lambert, \& Burlingame, 2000). De hecho, en términos totales, posee puntaje de corte para la población chilena de 73, lo que corresponde al puntaje que separa a la población funcional de la disfuncional. Por otro lado, el Índice de Cambio Confiable (ICC), que corresponde a la diferencia entre el puntaje inicial y el puntaje final, es de 17 en el caso de la población chilena, diferencia que indica que el cambio es estadísticamente significativo (von Bergen \& de la Parra, 2002).

Cuestionario de Evaluación de Funciones de la Personalidad (OPD-SQ). Se describió en la primera parte de este artículo.

Procedimiento. El estudio cuenta con la aprobación del Comité de Ética de la Escuela de Psicología de la Pontificia Universidad Católica de Chile, del Comité de Bioética del Servicio de Salud Metropolitano SurOriente, del Comité de Ética de la Escuela de Psicología de la Universidad de la Frontera y del Comité de Ética de la Universidad del Desarrollo.

En todos los casos se presentó a los participantes una carta de consentimiento de participación en el estudio, en la que se explicaba a los pacientes la relevancia de la investigación y los datos que serían requeridos, asegurando la confidencialidad de la información. Del mismo modo, en la carta se explicaba claramente que su participación era de carácter voluntario y que participar o no en el estudio no tendría ninguna consecuencia en su atención en el centro, así como también que se podrían retirar de la investigación cuando ellos lo estimaran, sin poner en riesgo su proceso terapéutico (en el caso de la muestra clínica). Los participantes de la muestra clínica no recibieron retribución económica por su participación en el estudio, 
mientras los participantes de la muestra no clínica recibieron una compensación económica equivalente a US $\$ 10-20$.

Después de firmar la carta de consentimiento, todos completaban los cuestionarios respectivos en los lugares adaptados para contar con confidencialidad y anonimato, con la presencia de ayudantes de investigación entrenados para responder dudas de ser necesario. El orden de aplicación de los instrumentos fue BDI-I, OPD-SQ y OQ-45.

Análisis de datos. Para evaluar la consistencia interna del OPD-SQ se calculó alfa de Cronbach para cada una de las dimensiones de la misma (subescalas). Luego, se calcularon los estadísticos descriptivos (media y desviación estándar) de cada una de las escalas utilizadas en este estudio, tanto para la muestra total como para las muestras clínica y no clínica por separado. También se evaluaron las diferencias de las medias en cada una de las escalas entre la muestra clínica y la no clínica mediante $t$ de Welch para dos muestras independientes, así como las diferencias de porcentajes entre ambas mediante el test exacto de Fisher. Finalmente, se calcularon las correlaciones bivariadas de las distintas escalas, utilizando $r$ de Pearson. Todos los análisis fueron realizados con el programa estadístico R v. 3.1.2. (R Development Core Team, 2011).

\section{Resultados}

\section{Comparación Muestra Clínica y No Clínica}

En la Tabla 5 se muestran los estadísticos descriptivos de los instrumentos utilizados en este estudio, separados por muestra clínica y no clínica. Se puede observar que, en relación a la sintomatología depresiva, la muestra no clínica presenta un promedio que se encuentra bajo el punto de corte propuesto para población chilena (14 puntos), mientras que la muestra clínica presenta una media por sobre dicho punto (Beck, 1961; Valdés et al., 2017), existiendo diferencia entre las dos muestras, $t(260)=-16,89, p<0,001, d=1,78$, 95\% IC [-19,72, -15,60]. La muestra clínica presenta una media de distrés psicológico (OQ-45) superior al puntaje de corte establecido en las normas nacionales (73 puntos) (von Bergen \& de la Parra, 2002).

En cuanto a los puntajes en el cuestionario OPD-SQ, la muestra clínica mostró puntajes mayores en el puntaje total de la escala que la muestra no clínica. Lo mismo se observó para cada una de las subescalas (ver Tabla 5). Esto es consistente con lo esperado, ya que implica que la muestra clínica presentaría niveles más bajos de funcionamiento estructural de la personalidad que la muestra no clínica.

\section{Consistencia Interna del OPD-SQ}

La muestra total presentó una consistencia interna que fluctúa entre aceptable (Vínculos Externos: $\alpha=0,71)$ y alta (Percepción de Sí Mismo: $\alpha=0,93$ ). La muestra no clínica presentó un patrón similar (ver Tabla 2). En la muestra clínica, sin embargo, la subescala Vínculos Externos presentó una consistencia interna cuestionable $(\alpha=0,65)$. El mal rendimiento de esta subescala puede deberse a una inconsistencia en las respuestas de los ítems que tienen que ver con "pedir ayuda". En la revisión de las respuestas por parte de los sujetos, un $25 \%$ de los casos responde de igual manera a los ítems: 12 "Me es fácil aceptar ayuda que otras personas me ofrecen" (por ejemplo, totalmente de acuerdo) y 28 "Me resulta difícil pedir ayuda a los demás" (también totalmente de acuerdo), lo que resulta contradictorio. Esto explica los bajos alfa de Cronbach encontrados en esta subescala, lo que se discutirá más adelante.

\section{Correlaciones Entre las Subescalas del OPD-SQ}

En la Tabla 6 se encuentran las correlaciones entre las subescalas del cuestionario OPD-SQ. Se observa que todas las subescalas correlacionan entre ellas de manera alta y directa. Esto indicaría que una mayor vulnerabilidad en uno de los aspectos que indican las subescalas se asocia con mayor vulnerabilidad en los de las otras. 
Tabla 5

Estadísticos Descriptivos de la Muestra No Clínica y Muestra Clínica en Sintomatología Depresiva, Estructura de Personalidad y Distrés Psicológico

\begin{tabular}{|c|c|c|c|c|c|c|c|c|}
\hline & \multirow{2}{*}{ Instrumento } & \multicolumn{2}{|c|}{ Muestra no clínica } & \multicolumn{2}{|c|}{ Muestra clínica } & \multirow{2}{*}{$t$} & \multirow{2}{*}{$p$} & \multirow{2}{*}{$\begin{array}{c}d \mathrm{de} \\
\text { Cohen }\end{array}$} \\
\hline & & Media & $D E$ & Media & $D E$ & & & \\
\hline BDI & & 6,25 & 5,32 & 23,92 & 12,00 & $-16,89$ & 0,001 & 1,78 \\
\hline \multicolumn{9}{|c|}{ OPD-SQ } \\
\hline & Puntaje total & 1,47 & 0,63 & 2,24 & 0,78 & $-9,37$ & 0,001 & 1,05 \\
\hline & Percepción del Sí Mismo & 1,40 & 0,96 & 2,43 & 1,13 & $-8,45$ & 0,001 & 0,97 \\
\hline & Percepción del Objeto & 1,29 & 0,66 & 2,08 & 0,87 & $-8,85$ & 0,001 & 0,99 \\
\hline & Autorregulación & 1,46 & 0,75 & 2,07 & 0,87 & $-8,99$ & 0,001 & 1,03 \\
\hline & Regulación Relación con Objeto & 1,41 & 0,80 & 2,33 & 0,94 & $-6,43$ & 0,001 & 0,74 \\
\hline & Comunicación Interna & 1,25 & 0,62 & 1,92 & 0,80 & $-8,14$ & 0,001 & 0,91 \\
\hline & Comunicación Externa & 1,58 & 0,65 & 2,14 & 0,82 & $-6,51$ & 0,001 & 0,73 \\
\hline & Vínculos Internos & 1,40 & 0,98 & 2,32 & 1,05 & $-7,65$ & 0,001 & 0,90 \\
\hline & Vínculos Externos & 2,00 & 0,75 & 2,67 & 0,77 & $-7,47$ & 0,001 & 0,89 \\
\hline \multicolumn{9}{|c|}{ OQ-45 } \\
\hline & Puntaje total & - & & 85,91 & 29,03 & - & & \\
\hline & Relaciones Interpersonales & - & & 18,19 & 6,88 & - & & \\
\hline & Rol Social & - & & 14,29 & 5,56 & - & & \\
\hline & Síntomas & - & & 53,55 & 19,78 & - & & \\
\hline
\end{tabular}

Tabla 6

Correlaciones Bivariadas Entre las Subescalas del OPD-SQ

\begin{tabular}{|c|c|c|c|c|c|c|c|}
\hline & 2 & 3 & 4 & 5 & 6 & 7 & 8 \\
\hline Percepción del Sí Mismo (1) & $0,81^{*}$ & $0,86^{*}$ & $0,71^{*}$ & $0,79^{*}$ & $0,76^{*}$ & $0,84^{*}$ & $0,69^{*}$ \\
\hline Percepción del Objeto (2) & & $0,77^{*}$ & $0,75^{*}$ & $0,68^{*}$ & $0,75^{*}$ & $0,81^{*}$ & $0,67^{*}$ \\
\hline Autorregulación (3) & & & $0,75^{*}$ & $0,71^{*}$ & $0,71^{*}$ & $0,80^{*}$ & $0,69^{*}$ \\
\hline Regulación Relación con Objeto (4) & & & & $0,58^{*}$ & $0,73^{*}$ & $0,72^{*}$ & $0,59^{*}$ \\
\hline Comunicación Interna (5) & & & & & $0,61^{*}$ & $0,73^{*}$ & $0,57^{*}$ \\
\hline Comunicación Externa (6) & & & & & & $0,74^{*}$ & $0,62^{*}$ \\
\hline Vínculos Internos (7) & & & & & & & $0,69^{*}$ \\
\hline Vínculos Externos (8) & & & & & & & \\
\hline
\end{tabular}

\section{Correlaciones del OPD-SQ con los Otros Instrumentos}

En la Tabla 7 se pueden observar las correlaciones del OPD-SQ total y de sus subescalas con el OQ-45 (distrés psicológico) y con la sintomatología depresiva (BDI). El OPD-SQ total presentó una correlación alta y directa con la sintomatología depresiva y con el OQ-45. Esto implica que mayor vulnerabilidad estructural se asocia a mayor severidad de los síntomas depresivos y distrés psicológico. Al observar las subescalas del OQ-45, se puede observar que también existe una correlación directa y alta del puntaje total de OPD-SQ con las subescalas Relaciones Interpersonales, Rol Social y Síntomas del OQ-45. Patrones similares pueden ser encontrados para cada una de las subescalas del instrumento OPD-SQ. 
Tabla 7

Correlaciones Bivariadas del OPD-SQ Total y sus Subescalas con Escalas de Sintomatología Depresiva y Distrés Psicológico

\begin{tabular}{lccccc}
\hline & OQ-45 total & OQ RI & OQ RS & OQ SD & BDI \\
\hline OPD-SQ Total & $0,79^{*}$ & $0,62^{*}$ & $0,50^{*}$ & $0,81^{*}$ & $0,79^{*}$ \\
Percepción del Sí mismo & $0,73^{*}$ & $0,54^{*}$ & $0,42^{*}$ & $0,77^{*}$ & $0,75^{*}$ \\
Percepción del Objeto & $0,64^{*}$ & $0,51^{*}$ & $0,39^{*}$ & $0,66^{*}$ & $0,69^{*}$ \\
Autorregulación & $0,64^{*}$ & $0,57^{*}$ & $0,45^{*}$ & $0,62^{*}$ & $0,62^{*}$ \\
Regulación Relación con Objeto & $0,78^{*}$ & $0,59^{*}$ & $0,52^{*}$ & $0,80^{*}$ & $0,75^{*}$ \\
Comunicación Interna & $0,68^{*}$ & $0,55^{*}$ & $0,41^{*}$ & $0,69^{*}$ & $0,66^{*}$ \\
Comunicación Externa & $0,65^{*}$ & $0,53^{*}$ & $0,44^{*}$ & $0,65^{*}$ & $0,63^{*}$ \\
Vínculos Internos & $0,74^{*}$ & $0,58^{*}$ & $0,47^{*}$ & $0,75^{*}$ & $0,72^{*}$ \\
Vínculos Externos & $0,55^{*}$ & $0,41^{*}$ & $0,33^{*}$ & $0,57^{*}$ & $0,63^{*}$ \\
\hline
\end{tabular}

Nota. ${ }^{*} p<0,001$. RI: Relaciones Interpersonales, RS: Rol Social, SD: Sintomatología, BDI: Inventario de Depresión de Beck.

\section{Discusión y Conclusiones}

En este estudio se ha introducido una versión en español del OPD-SQ (Ehrenthal et al., 2012), que se presenta como un instrumento de autorreporte que permitiría evaluar dimensionalmente capacidades y vulnerabilidades estructurales de la personalidad, tal como las entiende el sistema de diagnóstico OPD-2 (Grupo de Trabajo OPD, 2008), desde la perspectiva de los mismos pacientes. El instrumento se inscribe dentro de una comprensión dinámica y dimensional del funcionamiento de la personalidad, aportando una mirada complementaria y enriquecedora a los enfoques categoriales. El instrumento podría utilizarse, en la medida que avanza el proceso de validación, principalmente para investigación y triage, ya que deberán realizarse acuciosos estudios de comparación de la evaluación-codificación de la entrevista OPD-2 versus las respuestas al cuestionario, para un uso clínico que oriente decisiones terapéuticas.

La salud mental es influenciada por variables individuales, sociales y contextuales y estos determinantes interactúan dinámicamente (World Health Organization, 2012). Si bien el foco de este estudio estuvo puesto en la evaluación de vulnerabilidades individuales, particularmente el funcionamiento estructural de la personalidad, es necesario recordar la participación de factores de vulnerabilidad social y contextual — tales como pobreza, condiciones crónicas de salud, exposición a la violencia, discriminación o inequidad-en el desarrollo y curso de problemas psicológicos y mentales, como la depresión. El modo en que las vulnerabilidades del funcionamiento estructural de la personalidad pueden interactuar con dichos factores podría ser una línea de investigaciones futura.

En este trabajo se han presentado los fundamentos teóricos del instrumento, se ha descrito el procedimiento de traducción y traducción inversa, y reportamos primeros resultados de aplicaciones en pacientes con depresión y en una muestra no clínica, mostrando avances para el proceso de adaptación de la versión en español y evidencia respecto a una alta consistencia interna del instrumento y de las distintas subescalas que lo componen, excepto por la subescala Vínculos Externos. Como se ha señalado, esto se debería a una inconsistencia de las respuestas respecto al tema de la capacidad de "recibir ayuda", ya que los sujetos tendían a terminar respondiendo en un caso que le es fácil recibir ayuda (ítem 12) y por el otro, que les resulta difícil pedir ayuda (ítem 28), lo que es contradictorio. Probablemente, la redacción negativa, en términos de dificultad para hacer algo, atenta contra la comprensibilidad de este ítem en Chile, lo que deberá ser corregido en futuras versiones, previa consulta a los autores del instrumento.

Los resultados del estudio también muestran la capacidad del instrumento para diferenciar muestras clínicas de no clínicas, en el sentido de lo esperado, es decir, que la muestra clínica mostró puntajes mayores en el puntaje total de la escala que la muestra no clínica (a mayor puntaje peor funcionamiento estructural). Junto con esto, los análisis de correlaciones muestran que sujetos con un peor funcionamiento estructural de la personalidad tienden a un mayor distrés psicológico y a un mayor nivel de sintomatología depresiva. Estos resultados aportan primeras evidencias con respecto al contenido del cuestionario y a la relación con otras variables, en el sentido de que se espera que el instrumento, al evaluar funcionamiento estructural de la 
personalidad, diferencie sujetos sanos de sujetos que presentan algún trastorno, encontrando mejores niveles de funcionamiento en los primeros. Y, por otro lado, se esperaría que la carga sintomática sea mayor en pacientes con peor funcionamiento estructural y que la calidad de vida sea más baja en sujetos con más bajos niveles de funcionamiento estructural. Si bien estas son evidencias muy preliminares y generales, el estudio queda como base para futuras investigaciones con muestras más amplias y diversas y en cuyo diseño se puedan formular hipótesis más específicas.

Un próximo paso en el camino de generar evidencias respecto de la utilidad clínica del OPD-SQ sería, como se comentó anteriormente, contrastar resultados del cuestionario de autorreporte con la evaluación mediante jueces expertos del Eje IV OPD observando entrevistas OPD. Esto permitiría avanzar en cuanto al nivel de consistencia entre la auto-observación y la observación de expertos, respecto de las variables descritas en los dominios o capacidades estructurales del OPD-SQ. En relación a esto, es necesario mencionar que estudios en Alemania han encontrado evidencia que apoya esta consistencia (Dinger et al., 2014). Un camino complementario en este sentido es la posibilidad de contrastar los resultados del OPD-SQ con otros instrumentos que miden funcionamiento estructural, como, por ejemplo, la STIPO (Clarkin et al., 2004).

Entre las limitaciones de este estudio, cabe señalar el tamaño total de la muestra, que resulta insuficiente para análisis estadísticos más profundos, como sería un análisis factorial confirmatorio, el que, en esta etapa del estudio, no se encuentra como un objetivo que se pueda realizar. También las diferencias sociodemográficas entre las muestras clínica y no clínica llevan a tomar con cautela los resultados. Futuros estudios, que pongan énfasis en muestras más comparables, aportarán a la capacidad de discriminación del instrumento. El hecho de que algunos pacientes con diagnóstico de trastorno de personalidad hayan manifestado inquietud al responder algunos ítems, hace aconsejable, como ya se planteó, que el instrumento sea aplicado por un profesional de la salud mental, tal como se aconseja para algunas poblaciones respecto de instrumentos que miden síntomas depresivos, ansiosos o suicidalidad.

Por último, si bien en el estudio piloto se tomaron en cuenta los comentarios de los usuarios para corregir la redacción de algunos ítems, estas respuestas no se objetivaron mediante entrevistas cognitivas o estudios de pensamiento en voz alta (Ericsson \& Simon, 1980). En todo caso, la alta frecuencia de sujetos que respondieron habla favorablemente respecto de su comprensión y aceptabilidad en el medio local, apuntando también a un logro respecto al "salto" cultural entre su aplicación en Alemania y Chile.

En conclusión, es posible pensar que se está presentando un instrumento que podría ser útil para evaluar el funcionamiento de la personalidad que subyace a la patología depresiva, con amplias proyecciones tanto en la clínica como en la investigación. Un diagnóstico funcional se inscribe en la mirada contemporánea de los diagnósticos en salud mental (National Institute of Mental Health, s.f.), que van dejando atrás los diagnósticos categoriales para avanzar hacia un diagnóstico funcional personalizado que permitirá ayudar mejor a los pacientes, en este caso, al paciente depresivo.

\section{Referencias}

Alvarado, R., Vega, J., Sanhueza, G. \& Muñoz, M. G. (2005). Evaluación del Programa para la Detección, Diagnóstico y Tratamiento Integral de la Depresión en atención primaria, en Chile. Revista Panamericana de Salud Pública, 18, 278-286. https://doi.org/10.1590/S1020-49892005000900008

Bartholomew, K. \& Horowitz, L. M. (1991). Attachment styles among young adults: A test of a four-category model. Journal of Personality and Social Psychology, 61, 226-244. https://doi.org/10.1037/0022-3514.61.2.226

Beck, A. T., Steer, R. A. \& Carbin, M. G. (1988). Psychometric properties of the Beck Depression Inventory: Twenty-five years of evaluation. Clinical Psychology Review, 8, 77-100. https://doi.org/10.1016/0272-7358(88)90050-5

Beck, A. T., Ward, C. H., Mendelson, M., Mock, J. \& Erbaugh, J. (1961). An inventory for measuring depression. Archives of General Psychiatry, 4, 561-571. https://doi.org/10.1001/archpsyc.1961.01710120031004

Bender, D. S., Morey, L. C. \& Skodol, A. E. (2011). Toward a model for assessing level of personality functioning in DSM-5, part I: A review of theory and methods. Journal of Personality Assessment, 93, 332-346. https://doi.org/10.1080/00223891.2011.583808

Blatt, S. J. \& Luyten, P. (2009). A structural-developmental psychodynamic approach to psychopathology: Two polarities of experiences across the life span. Development and Psychopathology, 21, 793-814. https://doi.org/10.1017/S0954579409000431

Cardoso Ribeiro, C., Gómez-Conesa, A. \& Hidalgo Montesinos, M. D. (2010). Metodología para la adaptación de instrumentos de evaluación. Fisioterapia, 32, 264-270. https://doi.org/10.1016/j.ft.2010.05.001

Clarkin, J. F., Caligor, E., Stern, B. \& Kernberg, O. F. (2004). Structured Interview of Personality Organization (STIPO). White Plains, NY: Weill Medical College of Cornell University.

Dinger, U., Schauenburg, H., Hörz, S., Rentrop, M., Komo-Lang, M., Klinkerfuß, M., ... Ehrenthal, J. C. (2014). Self-report and observer ratings of personality functioning: A study of the OPD system. Journal of Personality Assessment, 96, 220-225. https://doi.org/10.1080/00223891.2013.828065 
Ehrenthal, J. C., Dinger, U., Horsch, L., Komo-Lang, M., Klinkerfuß, M., Grande, T. \& Schauenburg, H. (2012). Der OPDStrukturfragebogen (OPD-SF): Erste Ergebnisse zu Reliabilität und Validität [El cuestionario OPD de Estructura (OPD-SQ): resultados preliminares respecto a su confiabilidad y validez]. Psychotherapie, Psychosomatik, Medizinische Psychologie, 62, 25-32. https://doi.org/10.1055/s-0031-1295481

Ericsson, K. A. \& Simon, H. A. (1980). Verbal reports as data. Psychological Review, 87, 215-251. https://doi.org/10.1037/0033-295X.87.3.215

Florenzano, R. \& Guerrero, J. (2014). Trastornos de personalidad: desde Schneider al DSM-5. Revista Chilena de Neuro-Psiquiatría, 52(Suplemento 1), S38-S49. Extraído de https://www.sonepsyn.cl/revneuro/enero_marzo_2014/Suplemento_2014_1_Neuro_Psiq.pdf

Grupo de Trabajo OPD (2008). Diagnóstico Psicodinámico Operacionalizado (OPD-2): manual para el diagnóstico, indicación y planificación de la psicoterapia. Barcelona, España: Herder.

Hardt, J., Egle, U. T., Kappis, B., Hessel, A. \& Brähler, E. (2004). Die Symptom-Checkliste SCL-27 [La lista de comprobación de síntomas SCL-27]. Psychotherapie, Psychosomatik, Medizinische Psychologie, 54, 214-223. https://doi.org/10.1055/s-2003-814786

Hasler, G. (2010). Pathophysiology of depression: Do we have any solid evidence of interest to clinicians? World Psychiatry, 9, $155-161$. https://doi.org/10.1002/j.2051-5545.2010.tb00298.x

Herzberg, P. Y. \& Brähler, E. (2006). Assessing the big-five personality domains via short forms. European Journal of Psychological Assessment, 22, 139-148. https://doi.org/10.1027/1015-5759.22.3.139

Klein, D. N., Kotov, R. \& Bufferd, S. J. (2011). Personality and depression: Explanatory models and review of the evidence. Annual Review of Clinical Psychology, 7, 269-295. https://doi.org/10.1146/annurev-clinpsy-032210-104540

Lambert, M. J., Hansen, N. B., Umphress, V., Lunnen, K., Okiishi, J., Burlingame, G. M. ... Reisinger, C. W. (1996). Administration and scoring manual for the Outcome Questionnaire (OQ-45.2). Wilmington, DE: American Professional Credentialing Services.

Morey, L. C., Berghuis, H., Bender, D. S., Verheul, R., Krueger, R. F. \& Skodol, A. E. (2011). Toward a model for assessing level of personality functioning in DSM-5, part II: Empirical articulation of a core dimension of personality pathology. Journal of Personality Assessment, 93, 347-353. https://doi.org/10.1080/00223891.2011.577853

National Institute of Mental Health (s.f.). Research domain criteria (RDoC). Washington, DC: Autor. Extraído de http://www.nimh.nih.gov/research-priorities/rdoc/index.shtml

PDM Task Force (2006). Psychodynamic diagnostic manual. Silver Spring, MD: Alliance of Psychoanalytic Organizations.

$\mathrm{R}$ Development Core Team (2011). $R$ : A language and environment for statistical computing. Wien, Austria: $\mathrm{R}$ Foundation for Statistical Computing. Extraído de https://www.gbif.org/tool/81287/r-a-language-and-environment-for-statistical-computing

Salloum, I. M. \& Mezzich, J. E. (2011). Conceptual appraisal of the person-centered integrative diagnosis model. The International Journal of Person Centered Medicine, 1, 39-42. https://doi.org/10.5750/ijpcm.v1i1.20

Shedler, J. \& Westen, D. (2007). The Shedler-Westen assessment procedure (SWAP): Making personality diagnosis clinically meaningful. Journal of Personality Assessment, 89, 41-55. https://doi.org/10.1080/00223890701357092

Umphress, V. J., Lambert, M. J., Smart, D. W., Barlow, S. H. \& Clouse, G. (1997). Concurrent and construct validity of the Outcome Questionnaire. Journal of Psychoeducational Assessment, 15, 40-55. https://doi.org/10.1177/073428299701500104

Valdés, C., Morales-Reyes, I., Pérez, J. C., Medellín, A., Rojas, G. \& Krause, M. (2017). Propiedades psicométricas del Inventario de Depresión de Beck IA para la población chilena. Revista Médica de Chile, 145, 1005-1012. https://doi.org/10.4067/s003498872017000801005

Vermeersch, D. A., Lambert, M. J. \& Burlingame, G. M. (2000). Outcome Questionnaire: Item sensitivity to change. Journal of Personality Assessment, 74, 242-261. https://doi.org/10.1207/S15327752JPA7402_6

von Bergen, A. \& de la Parra, G. (2002). OQ-45.2, Cuestionario para Evaluación de Resultados y Evolución en Psicoterapia: adaptación, validación e indicaciones para su aplicación e interpretación. Terapia Psicológica, 20, 161-176. Extraído de https://www.researchgate.net/publication/263314562_oq-

452_cuestionario_para_evaluacion_de_resultados_y_evolucion_en_psicoterapia_adaptacion_validacion_e_indicaciones_para_su_a plicacion_e_interpretacion_oq-452_an_outcome_questionnaire_for_monitoring_ch

World Health Organization (2012). Risks to mental health: An overview of vulnerabilities and risk factors. Genève, Suiza: Autor.

Zimmermann, J., Ehrenthal, J. C., Cierpka, M., Schauenburg, H., Doering, S. \& Benecke, C. (2012). Assessing the level of structural integration using operationalized psychodynamic diagnosis (OPD): Implications for DSM-5. Journal of Personality Assessment, 94, 522-532. https://doi.org/10.1080/00223891.2012.700664

Fecha de recepción: Diciembre de 2016.

Fecha de aceptación: Enero de 2018. 


\section{Anexo}

Cuestionario de Funcionamiento Estructural (OPD-SQ)

\begin{tabular}{|c|c|c|c|c|c|}
\hline \multicolumn{6}{|c|}{ 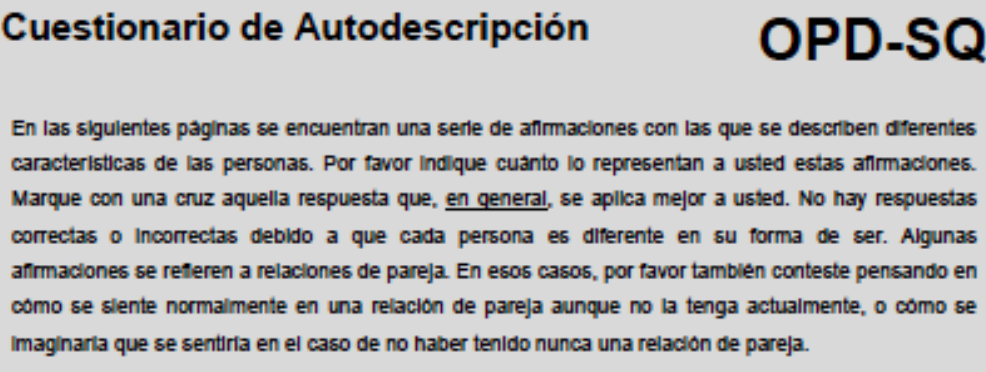 } \\
\hline & $\begin{array}{l}\text { Totalmente } \\
\text { en } \\
\text { desacuerdo }\end{array}$ & $\begin{array}{c}\text { Levemente } \\
\text { en } \\
\text { desacuerdo }\end{array}$ & $\begin{array}{l}\text { NI de } \\
\text { acuerdomi } \\
\text { desacuerdo }\end{array}$ & $\begin{array}{l}\text { Levemente } \\
\text { de acuerdo }\end{array}$ & $\begin{array}{l}\text { Totaimente } \\
\text { de acuerdo }\end{array}$ \\
\hline $\begin{array}{l}\text { 1. Me resulta muy dificll } \\
\text { describrme a mI } \\
\text { mismo(a). }\end{array}$ & 口 & व & व & व & 口 \\
\hline $\begin{array}{l}\text { Muchas veces actuo sin } \\
\text { pensar cuando estoy } \\
\text { eno(ado(a). }\end{array}$ & ם & 口 & व & 口 & व \\
\hline $\begin{array}{l}\text { 3. A veces me slento como } \\
\text { un extrafo(a) conmigo } \\
\text { mismo(a). }\end{array}$ & ם & $\square$ & $\square$ & व & 口 \\
\hline $\begin{array}{l}\text { 4. Me angustian las cosas } \\
\text { que Imagino o plenso. }\end{array}$ & ם & 口 & 口 & 口 & 口 \\
\hline $\begin{array}{l}\text { 5. Cuando plerdo algo o } \\
\text { alquien que yo quilero se } \\
\text { me mueve el piso. }\end{array}$ & व & व & व & व & 口 \\
\hline $\begin{array}{l}\text { 6. Me suelen acusar de ser } \\
\text { egoista en las relaciones. }\end{array}$ & ם & व & $\square$ & $\square$ & ㅁ \\
\hline $\begin{array}{l}\text { 7. A menudo los demas } \\
\text { perciben mil conducta de } \\
\text { forma muy distinta a lo que } \\
\text { era ml Intencion. }\end{array}$ & व & ㅁ & व & 口 & 口 \\
\hline $\begin{array}{l}\text { 8. Muchas veces tengo } \\
\text { emociones que no logro } \\
\text { entender. }\end{array}$ & व & 口 & व & व & 口 \\
\hline
\end{tabular}

\begin{tabular}{|c|c|c|c|c|c|c|}
\hline & & $\begin{array}{c}\text { Totalmente } \\
\text { en } \\
\text { desacuerdo }\end{array}$ & $\begin{array}{l}\text { Levemente } \\
\text { en } \\
\text { desacuerdo }\end{array}$ & $\begin{array}{l}\text { NI de } \\
\text { acuerdom! } \\
\text { desacuerdo }\end{array}$ & $\begin{array}{l}\text { Levemente } \\
\text { de acuerdo }\end{array}$ & $\begin{array}{l}\text { Totalmente } \\
\text { de acuerdo }\end{array}$ \\
\hline 9. & $\begin{array}{l}\text { Creo que las perdidas son } \\
\text { mas dolorosas para ml } \\
\text { que para otras personas. }\end{array}$ & ם & 口 & व & 口 & 口 \\
\hline 10. & $\begin{array}{l}\text { Muchas veces, sin querer, } \\
\text { me meto en situaciones } \\
\text { dificlles. }\end{array}$ & व & 口 & 口 & ㅁ & 口 \\
\hline 11. & $\begin{array}{l}\text { En el contacto con otras } \\
\text { personas soy mas torpe } \\
\text { que los demas. }\end{array}$ & 口 & 口 & 口 & 口 & 口 \\
\hline 12. & $\begin{array}{l}\text { Me es facll aceptar la } \\
\text { ayuda que otras personas } \\
\text { me ofrecen. }\end{array}$ & ם & 口 & 口 & 口 & 口 \\
\hline 13. & $\begin{array}{l}\text { Cuando alquilen me crittca, } \\
\text { me resuta dificill superario. }\end{array}$ & ه & 口 & ه & ם & ם \\
\hline 14. & $\begin{array}{l}\text { Las separaciones y } \\
\text { despedidas son muy } \\
\text { diflcles para ml. }\end{array}$ & ם & 口 & 口 & 口 & 口 \\
\hline 15. & $\begin{array}{l}\text { Percioo a los otros como } \\
\text { muy famillares o muy } \\
\text { extraf̂nos. }\end{array}$ & ם & 口 & 口 & 口 & 口 \\
\hline 16. & $\begin{array}{l}\text { Muchas veces no tengo } \\
\text { claro lo que estoy } \\
\text { sintendo. }\end{array}$ & व & 口 & 口 & 口 & 口 \\
\hline 17. & $\begin{array}{l}\text { Por ser tan poco crittco a } \\
\text { veces me llevo sorpresas } \\
\text { con las personas. }\end{array}$ & ם & 口 & व & 口 & 口 \\
\hline 18. & $\begin{array}{l}\text { A veces me slento como sl } \\
\text { los otros pudileran ver } \\
\text { dentro de ml y reconocer } \\
\text { mis pensamilentos o } \\
\text { sentimlentos. }\end{array}$ & 口 & 口 & 口 & 口 & 口 \\
\hline 19. & $\begin{array}{l}\text { ' A veces estoy tan furioso } \\
\text { que no puedo responder } \\
\text { por lo que hago. }\end{array}$ & ם & 口 & 口 & ㅁ & 口 \\
\hline 20. & $\begin{array}{l}\text { Cuando algulen lo esta } \\
\text { pasando mal, suelo } \\
\text { preocuparme. }\end{array}$ & 口 & 口 & 口 & 口 & 口 \\
\hline
\end{tabular}




\begin{tabular}{|c|c|c|c|c|c|c|}
\hline & & $\begin{array}{c}\text { Totalmente } \\
\text { en } \\
\text { desacuerdo }\end{array}$ & $\begin{array}{l}\text { Levemente } \\
\text { en } \\
\text { de日acuerdo }\end{array}$ & $\begin{array}{l}\text { NI de } \\
\text { acuerdonl } \\
\text { deascuerdo }\end{array}$ & $\begin{array}{l}\text { Levemente } \\
\text { de acuerdo }\end{array}$ & $\begin{array}{l}\text { Totalmente } \\
\text { de acuerdo }\end{array}$ \\
\hline $\mid 21$. & $\begin{array}{l}\text { A veces dudo sl algulen } \\
\text { esta pensando alqo de ml } \\
\text { o sl sollo es ml } \\
\text { Imaqinacion. }\end{array}$ & 口 & 口 & व & $\square$ & व \\
\hline 22. & $\begin{array}{l}\text { Me cuesta percibir mis } \\
\text { emociones. }\end{array}$ & 口 & व & $\square$ & व & व \\
\hline 23. & $\begin{array}{l}\text { Cuando me enolo, tendo a } \\
\text { hacer dẩo en m/s } \\
\text { relaciones. }\end{array}$ & व & व & $\square$ & व & $\square$ \\
\hline 24. & $\begin{array}{l}\text { A fin de cuentas, para mI } \\
\text { solo hay amlgos o } \\
\text { enemlgos, entremedio no } \\
\text { hay casl nada. }\end{array}$ & 口 & $\square$ & $\square$ & 口 & व \\
\hline 25. & $\begin{array}{l}\text { Mis fantasias e ideas me } \\
\text { vitallzan y enriquecen. }\end{array}$ & 口 & 口 & व & व & $\square$ \\
\hline 26. & $\begin{array}{l}\text { Muchas veces tengo } \\
\text { malos entendidos con } \\
\text { otras personas. }\end{array}$ & 口 & व & 口 & ם & 口 \\
\hline 27. & $\begin{array}{l}\text { Cuando plenso mucho } \\
\text { sobre mi mismo(a), tlendo } \\
\text { a contundirme. }\end{array}$ & 口 & व & 口 & व & $\square$ \\
\hline 28. & $\begin{array}{l}\text { Me resulta drficll pedir } \\
\text { ayuda a los demas. }\end{array}$ & 口 & व & व & व & व \\
\hline 29. & $\begin{array}{l}\text { S1 alqulen se acerca } \\
\text { demaslado, aunque sea } \\
\text { de forma ammistosa, me } \\
\text { ponqo tenso(a) o incluso } \\
\text { puedo entrar en panico. }\end{array}$ & 口 & 口 & $\square$ & व & $\square$ \\
\hline 30. & $\begin{array}{l}\text { Yo creo que } \\
\text { trecuentermente me } \\
\text { desculdo a ml mismo(a). }\end{array}$ & 口 & 口 & 口 & 口 & 口 \\
\hline |31. & $\begin{array}{l}\text { Me han dicho que muestro } \\
\text { mury poco m/s } \\
\text { sentilmlentos. }\end{array}$ & 口 & 口 & व & 口 & 口 \\
\hline
\end{tabular}

\begin{tabular}{|c|c|c|c|c|c|c|}
\hline & & $\begin{array}{l}\text { Totaimente } \\
\text { en } \\
\text { desacuerdo }\end{array}$ & $\begin{array}{l}\text { Levemente } \\
\text { en } \\
\text { deracuerdo }\end{array}$ & $\begin{array}{c}\text { NI de } \\
\text { acuerdoinl } \\
\text { deascuerdo }\end{array}$ & $\begin{array}{l}\text { Levemente } \\
\text { de acuerdo }\end{array}$ & $\begin{array}{l}\text { Totalmente } \\
\text { de acuerdo }\end{array}$ \\
\hline 32. & $\begin{array}{l}\text { Puede resultar pellaroso } \\
\text { delar que los demas se le } \\
\text { acerquen a uno } \\
\text { demaslado. }\end{array}$ & 口 & 口 & $\square$ & 口 & व \\
\hline 33. & $\begin{array}{l}\text { A menudo no tengo claro, } \\
\text { que es exactamente lo que } \\
\text { estoy sintlendo. }\end{array}$ & 口 & ם & ם & ם & ם \\
\hline 34. & $\begin{array}{l}\text { Tlendo a creer que } \\
\text { comentarlos y actos de } \\
\text { otros son sobre ml, } \\
\text { aunque posiblemente no } \\
\text { tenqan que ver conmiqo. }\end{array}$ & 口 & ם & ם & 口 & ם \\
\hline 35. & $\begin{array}{l}\text { Cuando algulen me habla } \\
\text { de sus problemas, estos } \\
\text { me quedan dando vueltas } \\
\text { por mucho rato. }\end{array}$ & 口 & ם & ם & व & ם \\
\hline 36. & $\begin{array}{l}\text { Normalmente me se } \\
\text { controlar, Incluso cuando } \\
\text { estoy hinviendo de rabla } \\
\text { por dentro. }\end{array}$ & 口 & ם & व & व & 口 \\
\hline 37. & $\begin{array}{l}\text { En el fondo ml cuerpo me } \\
\text { resulta ajeno. }\end{array}$ & 口 & 口 & व & ם & ם \\
\hline 38. & $\begin{array}{l}\text { En qeneral estoy } \\
\text { saltisfecho(a) conmiqo, tal } \\
\text { como soy. }\end{array}$ & 口 & 口 & $\square$ & 口 & 口 \\
\hline 39. & $\begin{array}{l}\text { A veces anoran cosas en } \\
\text { ml, que no calzan } \\
\text { conmilop. }\end{array}$ & 口 & ם & व & व & ם \\
\hline 40. & $\begin{array}{l}\text { No tengo una buena } \\
\text { autoestlma. }\end{array}$ & $\square$ & ם & $\square$ & व & व \\
\hline 41. & $\begin{array}{l}\text { Muchas veces slento tal } \\
\text { caos emocional en ml } \\
\text { Interior que nl siqulera } \\
\text { podria describin'o. }\end{array}$ & 口 & 口 & 口 & 口 & 口 \\
\hline 42. & $\begin{array}{l}\text { A veces expioto como } \\
\text { dilnamita. }\end{array}$ & 口 & 口 & 口 & $\square$ & 口 \\
\hline
\end{tabular}




\begin{tabular}{|c|c|c|c|c|c|c|}
\hline & & $\begin{array}{l}\text { Totalmente } \\
\text { en } \\
\text { deacecuerdo }\end{array}$ & $\begin{array}{l}\text { Levemente } \\
\text { en } \\
\text { deeacuerdo }\end{array}$ & $\begin{array}{l}\text { NI de } \\
\text { acuerdo/nl } \\
\text { deascuerdo }\end{array}$ & $\begin{array}{l}\text { Levemente } \\
\text { de acuerdo }\end{array}$ & $\begin{array}{l}\text { Totalmente } \\
\text { de acuerdo }\end{array}$ \\
\hline 43. & $\begin{array}{l}\text { A veces, cuando discuto } \\
\text { con los demas, lo veo } \\
\text { como: "o yo o el fella". }\end{array}$ & 口 & 口 & 口 & 口 & $\square$ \\
\hline 44. & $\begin{array}{l}\text { A veces lo unico que } \\
\text { slento es panico. }\end{array}$ & व & व & ㅁ & 口 & 口 \\
\hline 45. & $\begin{array}{l}\text { En ml vida, no he tenldo } \\
\text { muchas experienclas } \\
\text { buenas con otras } \\
\text { personas. }\end{array}$ & 口 & 口 & 口 & ㅁ & 口 \\
\hline 46. & $\begin{array}{l}\text { Yo creo que cuando } \\
\text { algulen a ml alrededor } \\
\text { tlene problemas, me } \\
\text { afecta mas que a los } \\
\text { demas. }\end{array}$ & 口 & 口 & 口 & 口 & 口 \\
\hline 47. & $\begin{array}{l}\text { Cuando ya no me las } \\
\text { puedo arreqlar solo(a), } \\
\text { pldo ayuda a los demás. }\end{array}$ & 口 & 口 & ㅁ & 口 & 口 \\
\hline 48. & $\begin{array}{l}\text { Prentero no pensar en ml, } \\
\text { porque sl to hago, solo veo } \\
\text { caos. }\end{array}$ & 口 & 口 & 口 & 口 & 口 \\
\hline 49. & $\begin{array}{l}\text { A veces juzgo mal como } \\
\text { ml conducta atecta a los } \\
\text { demas. }\end{array}$ & 口 & 口 & ㅁ & 口 & 口 \\
\hline 50. & $\begin{array}{l}\text { A menudo me slento } \\
\text { observado y controlado } \\
\text { cuando los otros saben } \\
\text { mucho de mL. }\end{array}$ & 口 & 口 & 口 & 口 & $\square$ \\
\hline 51. & $\begin{array}{l}\text { Suelo suffir una } \\
\text { IInsoportable tension } \\
\text { Interna, sin saber el mottivo }\end{array}$ & 口 & व & ㅁ & 口 & $\square$ \\
\hline 52. & $\begin{array}{l}\text { Me angustla sentirme una } \\
\text { persona distinta en } \\
\text { distlintas situaclones. }\end{array}$ & 口 & 口 & 口 & 口 & 口 \\
\hline 53. & $\begin{array}{l}\text { Creo que impresiono mas } \\
\text { blen como frio(a)e } \\
\text { Insensible. }\end{array}$ & 口 & 口 & ㅁ & ㅁ & 口 \\
\hline
\end{tabular}

\begin{tabular}{|c|c|c|c|c|c|c|}
\hline & & $\begin{array}{l}\text { Totalmente } \\
\text { en } \\
\text { desacuerdo }\end{array}$ & $\begin{array}{l}\text { Levemente } \\
\text { en } \\
\text { desacuerdo }\end{array}$ & $\begin{array}{c}\text { NI de } \\
\text { acuerdo/nl } \\
\text { deascuerdo }\end{array}$ & $\begin{array}{l}\text { Levemente } \\
\text { de acuerdo }\end{array}$ & $\begin{array}{l}\text { Totalmente } \\
\text { de acuerdo }\end{array}$ \\
\hline 54. & $\begin{array}{l}\text { Me han dicho repetidas } \\
\text { veces que tenqo muy poca } \\
\text { consideracion por las } \\
\text { necesidades de los } \\
\text { demas. }\end{array}$ & 口 & 口 & 口 & 口 & 口 \\
\hline 55. & $\begin{array}{l}\text { Mis ideas y tantasla me } \\
\text { ayudan slempre a } \\
\text { recuperar mi equilibrio } \\
\text { Interno. }\end{array}$ & 口 & 口 & 口 & 口 & व \\
\hline 56. & $\begin{array}{l}\text { Frecuentemente me } \\
\text { Involucro con personas } \\
\text { que solo posteriormente } \\
\text { revelan su verdadero } \\
\text { caracter. }\end{array}$ & 口 & 口 & 口 & 口 & व \\
\hline 57. & $\begin{array}{l}\text { Me resulta alficll hacer } \\
\text { algo bueno para mL. }\end{array}$ & 口 & 口 & 口 & 口 & 口 \\
\hline 58. & $\begin{array}{l}\text { A menudo soy incapaz de } \\
\text { percibir blen ml cuerpo. }\end{array}$ & 口 & 口 & 口 & 口 & 口 \\
\hline 59. & $\begin{array}{l}\text { Me llama la atencion que, } \\
\text { eventos supuestamente } \\
\text { Importantes, apenas } \\
\text { provoquen algun } \\
\text { sentimlento dentro de ml. }\end{array}$ & 口 & व & 口 & 口 & $\square$ \\
\hline 60. & $\begin{array}{l}\text { O la otra persona esta en } \\
\text { mi misma onda, o no } \\
\text { vamos a funclonar. }\end{array}$ & 口 & 口 & 口 & 口 & 口 \\
\hline 61. & $\begin{array}{l}\text { Una y otra vez me pasa } \\
\text { que interpretto de forma } \\
\text { completamente } \\
\text { equivocada los } \\
\text { comentarios de los demas. }\end{array}$ & 口 & 口 & व & 口 & 口 \\
\hline 62. & $\begin{array}{l}\text { A veces distruto el } \\
\text { delarme llevar por mls } \\
\text { pensamlentos y fantaslas. }\end{array}$ & 口 & 口 & 口 & 口 & 口 \\
\hline 63. & $\begin{array}{l}\text { Soy bueno(a) para meter } \\
\text { la pata en situaciones } \\
\text { soclales. }\end{array}$ & 口 & 口 & 口 & 口 & व \\
\hline
\end{tabular}




\begin{tabular}{|c|c|c|c|c|c|c|}
\hline & & $\begin{array}{l}\text { Totaimente } \\
\text { en } \\
\text { desacuerdo }\end{array}$ & $\begin{array}{l}\text { Levemente } \\
\text { en } \\
\text { deracuerdo }\end{array}$ & $\begin{array}{l}\text { NI de } \\
\text { acuerdo/nl } \\
\text { desacuerdo }\end{array}$ & $\begin{array}{l}\text { Levemente } \\
\text { de acuerdo }\end{array}$ & $\begin{array}{l}\text { Totaimente } \\
\text { de acuerdo }\end{array}$ \\
\hline 64. & $\begin{array}{l}\text { Muchas veces me slento } \\
\text { como un objeto, mas que } \\
\text { como un ser humano. }\end{array}$ & $\square$ & व & $\square$ & $\square$ & 口 \\
\hline 65. & $\begin{array}{l}\text { Muchas veces los otros } \\
\text { me rechazan sin que yo io } \\
\text { pueda entender. }\end{array}$ & ם & ם & व & 口 & ם \\
\hline 66. & $\begin{array}{l}\text { A menuodo tendo a pensar } \\
\text { en clertas personas que } \\
\text { podrian daflarme. }\end{array}$ & $\square$ & $\square$ & 口 & 口 & 口 \\
\hline 67. & $\begin{array}{l}\text { Me angustla pensar sobre } \\
\mathrm{ml} \text { mismmo(a). }\end{array}$ & 口 & $\square$ & 口 & 口 & ם \\
\hline 68. & $\begin{array}{l}\text { Parece que muchas veces } \\
\text { me paso de ingenuo(a). }\end{array}$ & व & ם & व & 口 & 口 \\
\hline 69. & Odilo mi cuerpo. & $\square$ & $\square$ & ㅁ & व & ם \\
\hline 70. & $\begin{array}{l}\text { ' Suelo tener tantaslas } \\
\text { aterradoras. }\end{array}$ & ם & व & ㅁ & 口 & 口 \\
\hline 71. & $\begin{array}{l}\text { A veces tengo temor de } \\
\text { que el IImlte entre yo y los } \\
\text { demas desaparezca. }\end{array}$ & ם & 口 & व & 口 & 口 \\
\hline 72. & $\begin{array}{l}\text { Establezco facilmente } \\
\text { contacto con otras } \\
\text { personas. }\end{array}$ & ם & ם & ㅁ & ㅁ & ם \\
\hline 73. & $\begin{array}{l}\text { Ms emociones son a } \\
\text { veces tan Intensas, que } \\
\text { me asustan. }\end{array}$ & व & व & व & व & 口 \\
\hline 74. & $\begin{array}{l}\text { Muchas veces me slento } \\
\text { como un castlllo de } \\
\text { nalpes, que puede } \\
\text { desmoronarse en } \\
\text { cualquier momento. }\end{array}$ & ם & ם & व & व & ם \\
\hline 75. & $\begin{array}{l}\text { Cuando converso de algo } \\
\text { Importante, a menudo la } \\
\text { corversacion se } \\
\text { transforma en una pelea. }\end{array}$ & ם & ם & व & व & ם \\
\hline
\end{tabular}

\begin{tabular}{|c|c|c|c|c|c|c|}
\hline & & $\begin{array}{l}\text { Totalmente } \\
\text { en } \\
\text { desacuerdo }\end{array}$ & $\begin{array}{l}\text { Levemente } \\
\text { en } \\
\text { degacuerdo }\end{array}$ & $\begin{array}{l}\text { NI de } \\
\text { acuerdo/nl } \\
\text { desacuerdo }\end{array}$ & $\begin{array}{l}\text { Levemente } \\
\text { de acuerdo }\end{array}$ & $\begin{array}{l}\text { Totalmente } \\
\text { de acuerdo }\end{array}$ \\
\hline 76. & $\begin{array}{l}\text { Nunca logro quedar } \\
\text { contento conmigo } \\
\text { mismo(a). }\end{array}$ & 口 & व & 口 & 口 & 口 \\
\hline 77. & $\begin{array}{l}\text { Me tienen que pasar } \\
\text { muchas cosas para que yo } \\
\text { leque a pedir ayuda. }\end{array}$ & 口 & ם & व & 口 & 口 \\
\hline 78. & $\begin{array}{l}\text { Me han dafiado mucho por } \\
\text { haberme equlvocado } \\
\text { respecto a una persona. }\end{array}$ & व & 口 & $\square$ & 口 & 口 \\
\hline 79. & $\begin{array}{l}\text { Me resuta diflcl } \\
\text { establecer contacto con } \\
\text { otras personas. }\end{array}$ & 口 & 口 & 口 & 口 & 口 \\
\hline 80. & $\begin{array}{l}\text { ' } \\
\text { Muchas veces me slento } \\
\text { Inutli y que sobro. }\end{array}$ & व & 口 & 口 & 口 & 口 \\
\hline 81. & $\begin{array}{l}\text { Muchas veces me es difcll } \\
\text { darme a entender frente a } \\
\text { los demas. }\end{array}$ & ם & ם & 口 & 口 & 口 \\
\hline 82. & $\begin{array}{l}\text { Frente a las separaciones } \\
\text { o perdiddas slento que se } \\
\text { me hunde el plso. }\end{array}$ & व & ם & 口 & 口 & 口 \\
\hline 83. & $\begin{array}{l}\text { Desearla que me fuera } \\
\text { mas facll tomar distancla } \\
\text { de los problemas de los } \\
\text { demass. }\end{array}$ & 口 & 口 & 口 & 口 & 口 \\
\hline 84. & $\begin{array}{l}\text { Para ml las personas o } \\
\text { son buenas o son malas. }\end{array}$ & ם & 口 & 口 & 口 & 口 \\
\hline 85. & $\begin{array}{l}\text { A veces, me es dificll } \\
\text { poder predecir cormo los } \\
\text { demas van a reaccionar } \\
\text { frente a ml. }\end{array}$ & ם & 口 & 口 & 口 & 口 \\
\hline 86. & $\begin{array}{l}\text { ' } \\
\text { Me qustarla poder sentir } \\
\text { mas intermamente. }\end{array}$ & व & 口 & 口 & 口 & 口 \\
\hline 87. & $\begin{array}{l}\text { En discuslones me puede } \\
\text { passar que ofendo a } \\
\text { personas que son } \\
\text { importantes para mL. }\end{array}$ & 口 & ם & 口 & व & 口 \\
\hline
\end{tabular}




\begin{tabular}{|c|c|c|c|c|c|c|}
\hline & & $\begin{array}{c}\text { Totalmente } \\
\text { en } \\
\text { desacuerdo }\end{array}$ & $\begin{array}{l}\text { Levemente } \\
\text { en } \\
\text { desacuerdo }\end{array}$ & $\begin{array}{c}\text { Ni de } \\
\text { acuerdo/ni } \\
\text { desacuerdo }\end{array}$ & $\begin{array}{l}\text { Levemente } \\
\text { de acuerdo }\end{array}$ & $\begin{array}{l}\text { Totalmente } \\
\text { de acuerdo }\end{array}$ \\
\hline & & . & . & . & . & . \\
\hline 88. & $\begin{array}{l}\text { No me trato tan bien a mí } \\
\text { mismo(a). }\end{array}$ & 口 & 口 & 口 & 口 & 口 \\
\hline 89. & $\begin{array}{l}\text { A menudo, cuando mi } \\
\text { pareja se me aferra } \\
\text { demasiado, siento sin } \\
\text { querer un intenso rechazo. }\end{array}$ & $\square$ & 口 & 口 & $\square$ & 口 \\
\hline 90. & $\begin{array}{l}\text { Mi experiencia es que } \\
\text { cuando se œonfia } \\
\text { demasiado en las } \\
\text { personas, uno puede tener } \\
\text { sorpresas desagradables. }\end{array}$ & 口 & 口 & 口 & 口 & 口 \\
\hline 91. & $\begin{array}{l}\text { Los demás me dicen que } \\
\text { siempre vuelvo a elegir a } \\
\text { los amigos equivocados. }\end{array}$ & $\square$ & $\square$ & 口 & $\square$ & 口 \\
\hline 92. & $\begin{array}{l}\text { Mis emociones suelen ser } \\
\text { como una montaña rusa. }\end{array}$ & $\square$ & 口 & $\square$ & $\square$ & $\square$ \\
\hline 93. & $\begin{array}{l}\text { Me siento incómodo(a) } \\
\text { cuando tengo que } \\
\text { acercarme a una persona } \\
\text { extraña. }\end{array}$ & 口 & 口 & 口 & $\square$ & $\square$ \\
\hline & 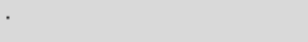 & & . & . & . & . \\
\hline 94. & $\begin{array}{l}\text { Suele pasar mucho tiempo } \\
\text { antes de que descubra el } \\
\text { lado oscuro de las } \\
\text { personas. }\end{array}$ & 口 & 口 & 口 & $\square$ & 口 \\
\hline 95. & $\begin{array}{l}\text { Algunas veces, después } \\
\text { de una discusión, me ha } \\
\text { dado mucha pena porque } \\
\text { siento que algo se } \\
\text { destruyó. }\end{array}$ & 口 & $\square$ & $\square$ & $\square$ & ㅁ \\
\hline
\end{tabular}

